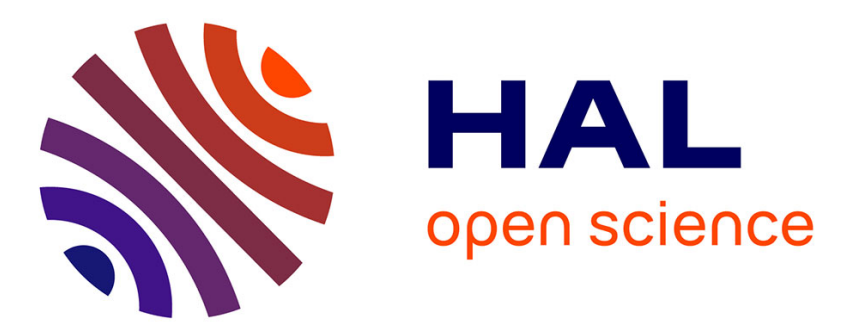

\title{
Awn Reduction and the Domestication of Asian Rice: A Syndrome or Crop Improvement Trait?
}

Serge Svizzero, Avik Ray, Debarati Chakraborty

\section{To cite this version:}

Serge Svizzero, Avik Ray, Debarati Chakraborty. Awn Reduction and the Domestication of Asian Rice: A Syndrome or Crop Improvement Trait?. Economic Botany, 2019, pp.1-12. 10.1007/s12231019-09465-0 . hal-02275855

\section{HAL Id: hal-02275855 \\ https://hal.univ-reunion.fr/hal-02275855}

Submitted on 2 Sep 2019

HAL is a multi-disciplinary open access archive for the deposit and dissemination of scientific research documents, whether they are published or not. The documents may come from teaching and research institutions in France or abroad, or from public or private research centers.
L'archive ouverte pluridisciplinaire $\mathbf{H A L}$, est destinée au dépôt et à la diffusion de documents scientifiques de niveau recherche, publiés ou non, émanant des établissements d'enseignement et de recherche français ou étrangers, des laboratoires publics ou privés. 
Awn Reduction and the Domestication of Asian Rice: A Syndrome or Crop Improvement Trait?

Serge Svizzero ${ }^{1}$, Avik Ray ${ }^{2, *}$, Debarati Chakraborty ${ }^{2,3}$

1- Faculté de Droit et d'Economie, Université de La Réunion, 15 Avenue René Cassin. CS 92003, 97744 Saint Denis Cedex 9, France, Tel: +262 2621382 58; ORCID: 0000-00033895-7273

2 - Center for studies in Ethnobiology, Biodiversity, and sustainability (CEiBa), B.G. Road, Mokdumpur, Malda - 732103, West Bengal, India; ORCID: 0000-0003-1662-7679

3 - Department of Molecular Biology and Biotechnology, University of Kalyani, Kalyani, India; ORCID: 0000-0002-1939-9889

*avikray@ceibatrust.org

Running title:

SVIZZERO, RAY AND CHAKRABORTY: RICE AWN REDUCTION

Words account: 7596; Abstract: 180. 


\begin{abstract}
Although wild progenitors of Asian cultivated rice have long awns, they are shorter or absent in domesticated landraces and cultivars. Thus, one may wonder when and why such transition from awned to awnless has occurred, i.e., is the reduction of awns a domestication syndrome trait or a trait emerged during crop improvement? The proponents of an evolutionary model of rice domestication consider the loss/reduction of seed dispersal aids as a key domestication syndrome trait, apart from the fixation of seed retention. We challenge this view by showing that early cultivators had incentives for selecting long awns before and even after the fixation of the non-shattering trait. This is because long awns prevented seeds predation by animal and facilitated the harvest by means of the basket beating method, that implies their presence improved yield and labor-efficiency. Our arguments also reveal that awns perhaps have persisted long after domestication and even after the introduction of sickles. Taken together, the reduction of awns may not fit to be a domestication syndrome trait but can most plausibly be considered as a crop improvement trait.
\end{abstract}

Keywords: Rice awn, Oryza sativa, domestication syndrome, crop evolution, predomestication cultivation, human behavioral ecology, non-shattering. 


\section{Introduction}

Awn, a characteristic of various plant families, is either a hair- or bristle-like appendage on a larger structure. Present in many grasses (Poaceae), awns typically extend from the lemmas of florets. When present, awns can vary in their rate of development, length, diameter and bristle length. They may be very long $(>40 \mathrm{~mm})$, long $(>20 \mathrm{~mm})$, short $(>5$ to $\leq 20 \mathrm{~mm})$ or very short $(<5 \mathrm{~mm})$ (Deb et al. 2005; Ikemoto et al. 2017). They may be straight or curved, single or multiple per floret, barbed or barbless.

In the wild, they have two primary functions. On the one hand, awns contribute to seed dispersal by wind and by sticking to passing animal fur, hence promote range expansion. Moreover, awns also contribute to the burial of seeds, given their features (e.g., the presence of tiny silica hairs on their surface) and their reaction to day to night variation of humidity, as demonstrated for wild wheat by Elbaum et al. (2007). While such function is vital in the wild, it is completely useless under cultivation because the plant reproduction is mediated by human intervention through seed sowing. On the other hand, their presence deters seed predation by animal such as birds, rodents and large mammals (Hua et al. 2015). This function is visible and thus it is clearly understood by farmers and was perfectly understood by early cultivators who therefore may have valued it from the beginning of cultivation. Awns also have a secondary function since they influence the development of a plant, e.g., grain number and grain size, and therefore have an impact on yield. For some cereals, such as wheat and barley, awns can be considered an alternate target for the improvement of grain yield through their known functions, including photosynthesis, carbohydrate storage, and efficiency of water-loss (Guo and Schnurbusch 2016). However, the correlation between yield and awn development is not clearly established in rice. Several authors have pointed out that the development of rice awns has a negative impact on yield (Luo et al. 2013; Gu et al. 2015; Jin et al. 2016). This is because, in contrast to wheat or barley awns, rice awns lack 
chlorenchyma (or contain only one vascular bundle; Luo et al. 2013) and cannot contribute to photosynthesis (Toriba et al. 2010). Nevertheless, in some rice landraces (e.g., Tipakhiya, Sathi) the presence of aids prevents water loss; moreover, the ablation of awn in these varieties results in grain sterility and irregular or random distribution within the panicles (Singh et al. 2009).

Although recent researches about the impact of the awn development in rice on yield are inconclusive, it is unlikely that early farmers were aware of such influence; because, such influence remains marginal in terms of yield. Because yield is also contingent on several biotic and abiotic factors, it was impossible for early farmers to distinguish and even to identify the (biological) influence of awns on yield. Therefore, we may plausibly assume that early farmers had not taken into account (because they were unable to do so) the secondary function of awns.

For Asian rice (Oryza sativa L.), most wild progenitors have long awns while most domesticates cultivars are awnless or have relatively shorter awns (Fuller et al. 2007). This difference between wild and domesticated species of cereals (including rice) and its importance in domestication lead most authors (e.g., Fuller 2007) to consider the loss or reduction of seed dispersal aids as one of the six traits defining the domestication syndrome (Hammer 1984). The domestication syndrome consists of traits that evolved under cultivation and were essential for the human agency to manipulate and make the plants dependent on them for survival.

There is, however, in the academic literature an endless debate concerning the duration of the domestication process. Some authors (Tanno and Willcox 2006; Fuller 2007, 2010; Brown et al. 2009; Purugganan and Fuller 2011; Asouti and Fuller 2013; Larson et al. 2014), mainly from archaeobotanical studies of the Near East, contend that domestication was a protracted process which have spanned from one (Tanno and Willcox 2006) to four millennia (Larson et 
al. 2014: 6142), mostly because artificial selection was unconscious (Gepts 2004; Purugganan and Fuller 2011). More precisely, it is believed that domestication has been reached progressively during a period called "pre-domestication cultivation" (Helbaek 1959) in which cultivated plants were morphologically and genetically wild. One consequence of this presumed protracted process is that some traits may have occurred before the fixation of the seed retention and therefore should be considered as domestication syndrome traits.

For other authors, the domestication was rapid - an event rather than a process - lasted about few decades or at worst few centuries (Zhang et al. 2009; Abbo et al. 2014a, 2014b, 2017; Tzarfati et al. 2013) owing to "the superiority of human mind". They distinguish domestication traits which were crucial for the domestication from other changes, including the loss or reduction of awns, which rather should be considered as an improvement featuring crop evolution (Abbo et al. 2014b). Indeed, these authors consider that traits - such as the reduction of awns - showing a phenotypic continuum between wild and domesticated gene pools mostly reflect post-domestication diversification rather than the pristine domestication episode.

This latter conclusion - that the reduction of awns should be considered as a crop improvement trait (or as a post-domestication trait or a diversification trait) - is at odds with the former view in which awns reduction is considered as a domestication syndrome trait. Our aim in this paper is to contribute to this debate, i.e., should we consider the reduction of awns in Asian rice as a domestication trait or as a crop improvement trait? We focus on Asian rice since Abbo et al. (2014b) have only considered Near-eastern cereals and legumes in their distinction between crucial domestication traits and crop improvement traits.

For this purpose, we examine the prevalent evolutionary model of rice domestication (Fuller 2007; Fuller et al. 2007; Fuller and Allaby 2009) and its main conclusion that the reduction of awns should be considered as a domestication trait since it is believed that (a) it is the result of 
changes in natural selection and (b) it has been achieved before the fixation of the nonshattering trait (section 2). Then, we demonstrate that both conclusions (a and b) of this evolutionary model can hardly be supported by either archaeological evidence or genetic analysis, or phenotypic analysis of current rice varieties (section 3). In the sequel of the paper, we challenge the conclusion of the prevalent evolutionary model of rice domestication. First it is unclear how natural selection might have led, in only few millennia, to the reduction of awns. Moreover we demonstrate that during the pre-domestication cultivation period, human selection has been, consciously and/or unconsciously, in favor of long awns since the latter deter seed predation by animals and facilitate the harvest by means of the basket beating method (section 4).

Second, we provide three complementary reasons explaining why human activities may have fostered the presence of long awns even after the fixation of the non-shattering trait, and even beyond the introduction of the sickle used for harvesting domesticated rice (section 5).

Our rationale leads us to conclude that the reduction of awns should not be considered as a domestication trait but rather as a crop improvement trait. Moreover, we have identified some reasons explaining the persistence of long awns after initial domestication, and even in current landraces, despite strong selection against their presence, especially during the last decades as induced by the "green revolution" (see e.g. Hu et al. 2011; Pingali 2012).

\section{Awns in an Evolutionary Model of the Rice Domestication Syndrome}

The domestication syndrome can be defined as the collection of characteristic phenotypic traits associated with the genetic changes to a domesticated form of an organism from a wild progenitor (Hammer 1984). For grain crops, the domestication syndrome usually includes six morphological and physiological traits (Harlan et al. 1973; Hammer 1984; Fuller 2007) which includes the loss/reduction in seed dispersal aids. Some selective pressures exerted by cultural 
exercise (e.g., the sowing method) may have an influence on several domestication traits while other selective pressures are trait-specific (Allaby 2010). Then, since the selective pressures induced by human actions are not synchronous, there is no a priori reason to assume that the six traits defining the domestication syndrome have evolved simultaneously. In other words, some traits may have been fixed before the others (Allaby 2010). Given our aim, the question is to know whether the reduction of awns has occurred either before or long after the fixation of the non-shattering trait.

Certain evolutionary models explain when and why the transformation from awned to awnless varieties has occurred (Fuller 2007; Fuller et al. 2007; Fuller and Allaby 2009). These authors assume that early selection pressures were ultimately driven by the pre-domestication sowing activities. As humans started to plant seeds, it is argued that this should have relaxed natural selection in favor of maintaining natural dispersal aids, i.e., leading to the loss/reduction in awns and hairs (Harlan et al., 1973). As stated by (Fuller 2007: 905, 913) this transformation "(This) can be considered to have come about by the removal of natural selection for effective dispersal, and once removed metabolic 'expenditure' on these structures is reduced." Similarly Fuller and Allaby (2009: 252) stated that "Once natural selection was removed to maintain such dispersal aids, smaller and fewer appendages may have developed by genetic drift (...). However, it may also be the case that selection operated by reducing metabolic 'expenditure' creating a parallel trend towards less barbed and hairy cereal spikelets, which can be observed across species."

Then, and according to the model developed by these authors, the reduction of seed dispersal aids might have evolved under initial cultivation and should be regarded as part of 'semidomestication' (Fuller 2007), or in other words, it contributes to the possibility of metastable crops of intermediate domestication (e.g. larger grains, no or shorter hooks or awns but still with a brittle rachis) occurring for substantial periods of time (Fuller et al. 2010; Allaby 2010: 
939). Since the term 'semi-domesticated' has been proposed for populations which show other changes associated with domestication prior to fixation of the non-shattering trait (Fuller and Allaby 2009: 240), this clearly means that according to the authors, the reduction of awns has occurred before the fixation of the non-shattering trait, the latter being hindered by various artificial selective pressures stemmed from harvesting methods (Fuller 2007) and threshing practices (Fuller et al. 2010).

The main conclusions of this model about the evolution from awned to awnless varieties, i.e., how/why and when such transition has occurred, can be summarized as follows:

(a) An answer to the "how and why" queries: the reduction of awns is the result of changes of the natural selection which has occurred from the beginning of the period called "predomestication cultivation",

(b) An answer to the "when" query: the reduction of awns has been achieved before the fixation of the non-shattering trait, i.e., before the end of the period called "pre-domestication cultivation".

One consequence of both conclusions ( $a$ and $b$ ) is that the reduction of seed dispersal aids is clearly conceived as a trait pertaining to the domestication syndrome, or in other words, was necessary for the achievement of the domestication in Asian rice.

We challenge the conclusions of this prevalent evolutionary model of rice domestication. First it is unclear how natural selection might have led, in only few millennia, to the reduction of awns since even for proponents of the protracted model of domestication, the predomestication cultivation period should have spanned from one to four millennia. It should be noted that such claim is not detailed by its authors, i.e., it remains unclear how natural selection might have operated against the presence of awns. Moreover, we demonstrate in sequel (sections 4 and 5) that during the pre-domestication cultivation period, human selection has been, consciously and/or unconsciously, in favor of long awns since the latter 
deter seeds predation by animals and facilitate the harvest by means of the basket beating method. In other words, the reduction of awns cannot have occurred before the fixation of the non-shattering trait.

\section{Some Difficulties to Assess the Transition From Awned to Awnless}

\section{Archaeological}

From an archaeological point of view, what is established for the Lower Yangtze region is a chronologically protracted evolutionary process over 3000-4000 years, reaching the domesticated non-shattering state by ca. 3800 BC (Fuller et al. 2009; Fuller et al. 2014; Fuller et al. 2016). However, the timing of awn reduction cannot be deduced from archaeological records. Indeed, there is a little archaeological evidence on the evolutionary trend leading from awned wild cereals to awnless domestic cereals. The main problem is that hairs and awns survive poorly in the archaeological records (Fuller 2007; Fuller and Allaby 2009). Even though there are exceptions, i.e., some archaeological records of awns exist, as for instance in rice (Fuller and Allaby 2009: 252-253), but too few samples of archaeological rice awns have been studied to elucidate the temporal trends in such evidence, nor has comparable data from other taxa been examined. As stated by Fuller (2007: 905), "Of particular importance to the archaeobotanist are those changes that can be identified in archaeological material. This is likely to include nos. 1-4, although no. 4 is only preserved in certain kinds of seeds, and no. 2 may be difficult to recognize because hairs are often destroyed by carbonization. For this reason, especially for most cereals, it is criteria 1 and 3 that archaeologists look at." [The following criteria are used in this quotation: criteria 1: elimination/reduction of natural seed dispersal; criteria 2: reduction in seed dispersal aids; criteria 3: trends towards increasing seed/fruit size; and criteria 4: loss of germination inhibition.] 


\section{Genetics}

On the genetic ground, seed awning in rice is not featured by a simple "one trait-one gene" relationship. On the contrary, several major genes/QTL associated with awning have been recently identified, such as An-1 (Luo et al. 2013), LABA1 (Hua et al. 2015), DL and OsETT2 (Toriba and Hirano 2014), RAE2 (Bessho-Uehara et al. 2016). In addition, several genes/QTL have also a minor influence on awning; as reported by $\mathrm{Hu}$ et al. (2011), a total of 31 loci have been found to be associated with awn presence. Since many genes are involved in awn formation (i.e., polygenic trait), and also because some of them may have pleiotropic effects, the genetics of seed awning is complex. More importantly, the causal mutation in a single gene may not be sufficient to explain the phenotypic transformation from awned to awnless (see e.g. Ishikawa et al. 2010). Therefore, despite recent advances in our understanding of the genetic architecture and molecular genetic basis of phenotypic changes favored during domestication and later crop improvement (Olsen and Wendel 2013; Meyer and Purugganan 2013), it remains very hard to explain by means of genetic analysis when and why awns underwent reduction.

\section{Phenotypic diversity}

Botanical studies of current rice landraces and cultivars show that a broad range of situations exists. In fact, the high phenotypic diversity related to awn length (as shown below in Table 1) is present at several hierarchical levels:

Table 1: A non-exhaustive list of Indian rice landraces having different awn length (in millimeter) taken from Deb et al. (2005).

\begin{tabular}{|l|l|l|l|}
\hline Awnless rice & Very short awn rice & Short awn rice & Long/very long awn rice \\
\hline Agni-sal & Budbud-Sal (1.7) & Lal Panati (9.0) & Kalma (21) \\
\hline Bansh Kathi & Chaitanya (3.25) & Nata (11.1) & Shimul Kuri (28.1) \\
\hline
\end{tabular}


Table 1: A non-exhaustive list of Indian rice landraces having different awn length (in millimeter) taken from Deb et al. (2005).

\begin{tabular}{|l|l|l|l|}
\hline Chini Atap & Jal Kamini (2.07) & Niroja (7.47) & Sada Jira/Sada Bhog (23.2) \\
\hline Dumur-Sal & Kalo Boro (3.0) & Noichi (8.5) & Shatia (33.0) \\
\hline Gandheswari & Kanakchur (3.33) & Parmai-Sal (5.87) & Bhim-sal (33.7) \\
\hline Jamai-Sal & Kuro Bagar (4.7) & Ratul Aush (8.6) & Gangajali (37.9) \\
\hline Kaminibhog & Marich-Sal (3.2) & Sada Kaya (9.27) & Kaya Kelas (40.5) \\
\hline Olee & Radhuni Pagal (2.8) & Shotput (9.2) & Kakua (53.1) \\
\hline
\end{tabular}

i) Between the (most) wild progenitors (which are awned) and the domesticated cultivars

(which are awnless). For instance, according to Ikemoto et al. (2017), the awns are barbed and their length is between 50 to $90 \mathrm{~mm}$ in (the wild) O. rufipogon W360, while barbless awns are less than $10 \mathrm{~mm}$ in (the domesticated) O. sativa Nipponbare.

ii) Within wild species, as well as within domesticated species; even though most wild species have long awns, there are few exceptions, such as Oryza meyeriana, O. schlechteri and $O$. granulata, which are awnless (Fuller et al. 2007). Similarly, while most domesticated landraces are awnless or have only short awns, some are awned, including long ( $>20 \mathrm{~mm})$ and very long (> $40 \mathrm{~mm}$ ) awns, e.g., in an aus strain, Kasalath (15 to $40 \mathrm{~mm}$ ) (Toriba and Hirano 2014). Such diversity of awn length in modern landraces is illustrated in Figure 1. 


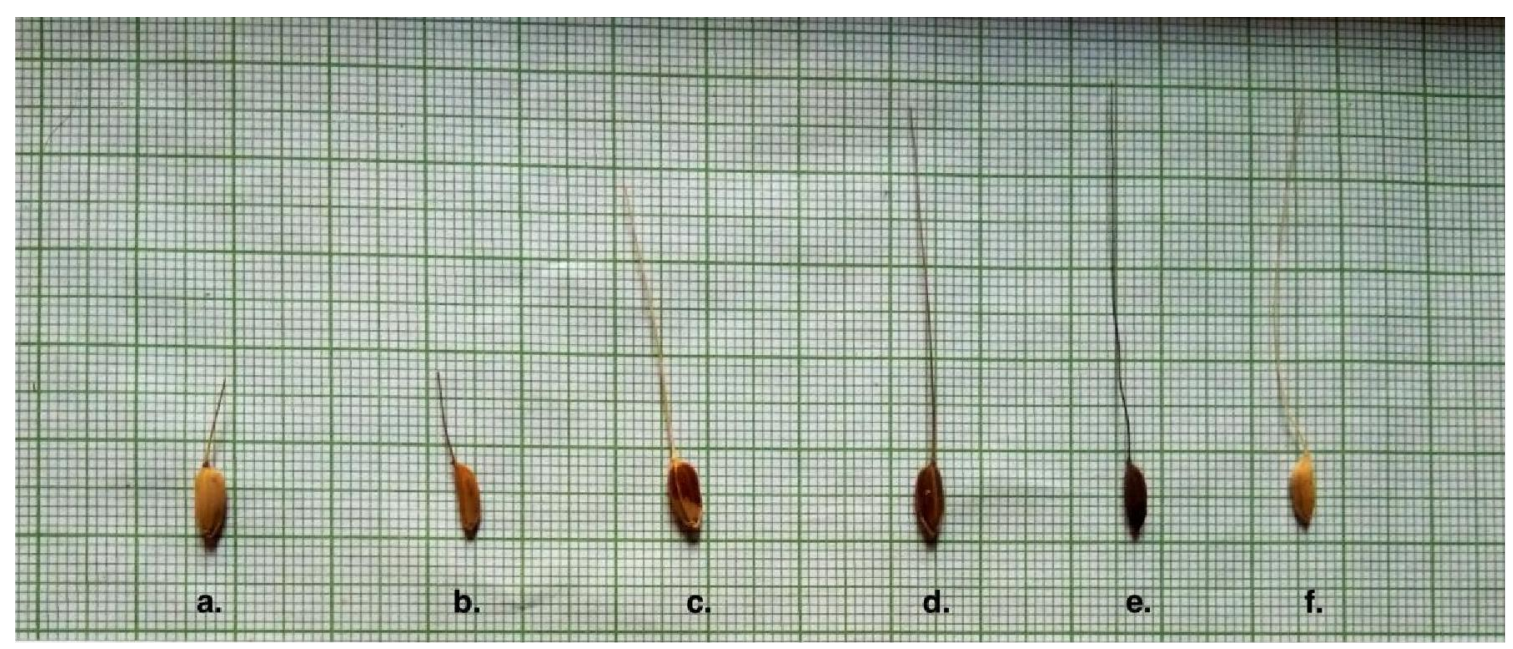

Figure 1: A spectrum of diversity of awn length in modern landraces (a. Rahapanjar, b. Sada Kaya, c. Shimul kuri, d. Gangajali, e. Kalonunia, f. Tulaipanji) (in mm)

iii) Intra-species or inter-population variation, i.e., for any given species, the awn length is different according to the environment in which the plants are growing (see e.g. Magwa et al. 2016: 641, table 1) for a comparison between two Chinese regions, Hainan and Wuhan). iv) Within the same wild as well as domesticated species, the awn length is variable between primary and secondary branches or tillers, and among the five uppermost spikelets on the top primary branch in the panicles (Ikemoto et al. 2017; Ishii and Ishikawa 2018).

Thus it can be correctly said that awn length in rice denotes a phenotypic continuum where length varies from absent or very short $(<5 \mathrm{~mm}$; see table 1$)$ to as long as $76.4 \mathrm{~mm}$ in Gaoyangdiandahongmang, a japonica variety (Ikemoto et al. 2017; Magwa et al. 2016), a range almost overlaps with that of wild rice which can harbor both short and long awns (Deb et al. 2005; Ikemoto et al. 2017: Table 2).

The phenotypic diversity of awn length can hardly be used to infer when and why the reduction of awns has occurred. However, there is one way in which it can be interpreted. Indeed, if selection (natural and/or artificial) against awns was ancient and strong, it should 
have led to a very low level of phenotypic diversity caused by strong selection pressures (as in purifying selection). In contrast, it is the converse that we observe nowadays, i.e., a high level of phenotypic diversity in awn length, which means it is unlikely that selection against awns was ancient and strong.

\section{The Selection of Long Awns by Early Farmers During the Pre-Domestication}

\section{Cultivation}

Since we have identified the primary and secondary functions of awns, we may now turn to the early cultivator's decision concerning the presence of awns. In order to decipher this, we have to identify which stages from sowing to storage were influenced by the presence of awns and how. These stages and the effect of awns are summarized in Table 2:

Table 2: Influence of awns on the yield, harvest, and post-harvest efficiency, when the basket beating method is used for harvesting, and that most - if not all panicles are shattering

\begin{tabular}{|l|l|l|}
\hline & $\begin{array}{l}\text { Awned } \\
\text { Long awns }\end{array}$ & $\begin{array}{l}\text { Awnless } \\
\text { No or short awns }\end{array}$ \\
\hline $\begin{array}{l}\text { Yield } \\
\text { or pre-harvest production }\end{array}$ & high & low \\
\hline $\begin{array}{l}\text { Harvest efficiency } \\
\text { with the basket beating }\end{array}$ & high & low \\
\hline $\begin{array}{l}\text { Efficiency of post-harvest operations } \\
\text { threshing, processing, storage }\end{array}$ & low & high \\
\hline
\end{tabular}

With long awns, we may expect the following results: 
- The yield (defined as the pre-harvest production) is higher because long awns are preventing seed predation.

- The harvest efficiency is higher because the long awns cling to the basket, and therefore less seeds are lost during the harvest. It is likely that during the initial cultivation period, the basket beating method was used; even before pre-domestication cultivation has started, such method was already used by hunter-gatherers in order to collect wild seeds. Moreover, it is claimed that the use of sickles for rice harvesting is an exaptation, i.e., the sickles have been used long after rice domestication (i.e., the fixation of non-shattering) has been achieved (Fuller 2007; Maeda et al. 2016). For instance, in the Lower Yangtze region, while rice domestication has occurred around 3800 to $4000 \mathrm{BC}$, the sickles or harvesting knives for harvesting whole panicles arrived perhaps around 3300 BC (Fuller et al. 2008). [Although we use the term "basket beating" in sequel, it broadly encompasses various equivalent harvesting techniques such as the basket swinging or the sweeping basket. Knotting or bundling can also be considered as equivalent methods because they are more efficient when awns are long.] - The efficiency of post-harvest operations with awn is however lower than that with awnless. This is usually claimed, even nowadays, to justify the selection against long awns, because their presence hinders threshing, processing, and storage operations. One may however contest such conclusion, i.e., the difference of efficiency of post-harvest operations was probably not as important as currently claimed. As pointed out by Tzarfati et al. (2013), the observations on traditional farming practices highlight that awn removal by brief firing could have been a part of the ancient post-harvest handling. In other words, if early farmers had also practiced brief firing for awn removal, then the awns were no longer a problem for the processing and the storage operations.

By transposing early cultivators to what Optimal Foraging Theory (Winterhalder and Kennett 2006) considers as an optimal behavior for hunter-gatherers, it is possible to deduce what 
should have been the optimizing behavior of early cultivators. The latter can be defined as the maximization of yield and labor efficiency (Svizzero 2018). Hence, it emanates from Table 2 and its associated explanations that early cultivators may have had strong incentives to maintain long awns since their presence was leading to a higher yield and a higher efficiency of their labor. The artificial selection in favor of long awns may have been twofold, conscious and/or unconscious (according to the usual terminology; see e.g. Zohary 2004).

On the one hand, it may have been conscious or intended. Since early farmers were aware that long awns prevented seed predation and thus improved yield, they may have selected seeds with long awns in order to be used in next sowing. On the other hand, selection of long awns may have been unconscious (or automatic) and implied by the harvesting technique, namely the basket beating. Furnished with such harvesting technique, seeds with long awns were easily collected, as previously explained. Therefore, basket beating could have imparted selection pressure in favor of long awns and preferentially selected awned grains over awnless ones. As a consequence, the fraction of awned type could have been higher than awnless in each harvest. So, during the post-harvest phase, in absence of selection against long awns, the frequency of long awns would have gradually increased in each harvest and thus in each sowing. Therefore, whether conscious or unconscious selection were operative, the gradual increment of awned type in the population could have taken place leading to the fixation of awns in the population, which is discordant with the premise of the awn reduction. We invoke that, as stated in section 2, several authors (Fuller 2007; Fuller et al. 2007; Fuller and Allaby 2009) considered the awns as a domestication trait because it is assumed that their reduction had started before the fixation of the non-shattering trait and was a result of relaxation of natural selection. This is at odds with the conclusion that we have reached in the present section. When cultivation has started, the artificial selective pressures consciously and 
unconsciously induced by early cultivators were stronger and favoring the presence of long awns.

\section{The Persistence of Long Awns Beyond the Domestication Period}

The conclusion of the previous section is that it is unlikely that the reduction of awns had occurred before the full domestication, and prior to the fixation of the non-shattering trait. However such conclusion is not sufficient per se for claiming that the reduction of awns is a crop improvement trait rather than a domestication syndrome trait. There is no reason that the six traits defining the domestication syndrome for cereals occur simultaneously. So, if the reduction of awns had occurred just after the fixation of seed retention, then it should nevertheless be considered as a syndrome trait. In other words, what we have now to demonstrate is that the reduction of awns has started long after the full domestication, and therefore should be considered as a crop improvement trait. For such purpose, we develop three different, but complementary lines of arguments.

The first argument is illustrated by the following figure 2 :

Figure 2: The comparative evolution of food production technologies, harvesting methods, and the presence of awns (from the Mesolithic to nowadays).

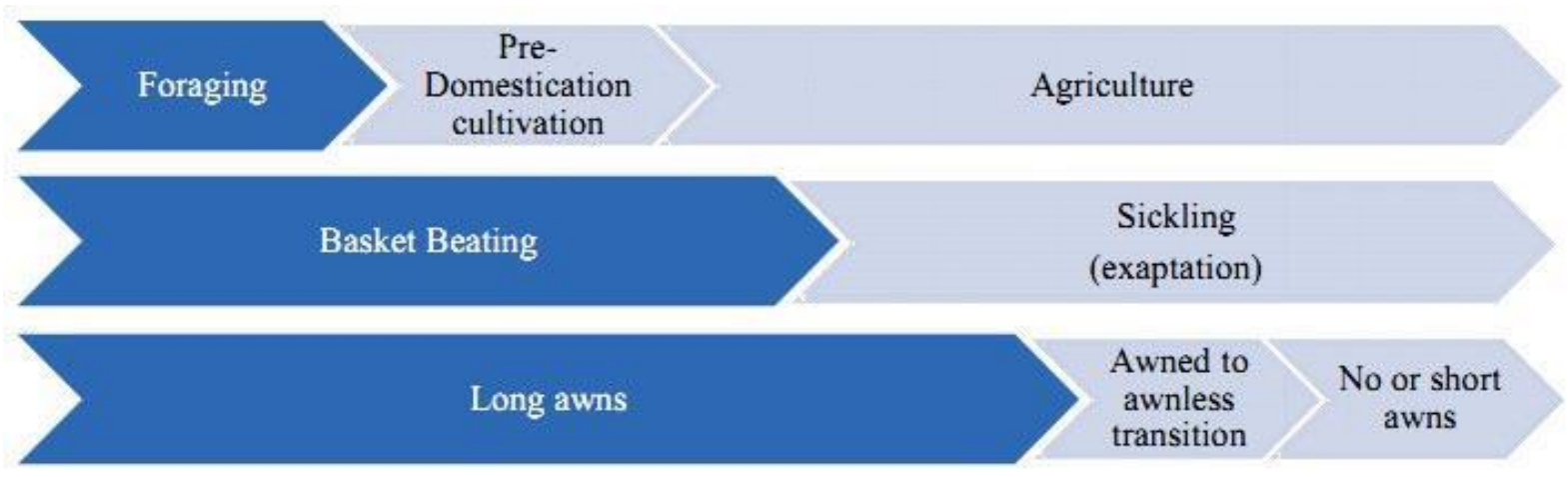


In figure 2, the first arrow with forward time direction depicts the evolution from foraging to farming. It is now widely agreed that there were some intermediate stages between these two polar cases. Harris (1989), for instance, assumed the existence of several stages pertaining to the people-plant interaction. Between 'pure' foraging for wild species and agriculture based on domesticated plants, there is an intermediate stage in which wild plants were cultivated. In the academic literature this stage has been labeled as "pre-domestication cultivation" (Helbaek 1959), meaning the morphologically and genetically wild plants were cultivated (see e.g., Fuller 2007). Thus, the end of this stage - and then the start of agriculture - coincides with the domestication of plants (even though all the traits defining the domestication syndrome were not fixed at that time).

In figure 2, the second row recalls that using a sickle for rice harvesting is an exaptation, i.e., the sickle has been introduced after the fixation of seed retention (i.e., after the end of the predomestication cultivation episode) (Fuller 2007). This implies that the basket beating method had been used even after the full domestication; even when the non-shattering trait is considered as fixed, the basket beating method can still be used for harvesting. This is because the genetic mutation leading to seed retention, such as in sh4 locus, weakens but does not eliminate the shattering phenotype (Doebley et al. 2006). In fact, the early cultivators whatever the harvesting method they used - were confronted with a trade-off: on the one hand they need seed that stay long enough on the plant to be harvested and, on the other hand, they wished seed to subsequently be freed quite easily from the plant by threshing. So, even when the non-shattering trait was fully or partially fixed, they may have used the basket beating method. However, it is likely that this harvesting technique had lost a part of its efficiency as now the beating may not completely dislodge the grains or more beating (i.e., labor) per spike (i.e., yield) had been performed to do so. Therefore, we may infer from the previous statement that the progressive fixation of seed retention has gradually decreased the efficiency of the 
basket beating and perhaps had fostered the introduction of a new harvesting technique, namely sickling.

When the sickle was introduced, this had changed the labor-efficiency of the harvest. By comparison with the second row of table 2 , the labor efficiency by sickling had become low when seeds were awned and high for awnless seeds. In other words, the strong incentives that cultivators enjoyed previously in favor of long awns had been weakened. Then two situations may have happened. First, and because the labor efficiency of harvest and post-harvest operations was lower with long awns, and in environment where seeds predation was weak, the farmers have decided to select against long awns. In this case, the transition from awned to awnless seeds is directly correlated with the introduction of the sickle. Second, in situation where seed predation was strong, and even though the labor efficiency of harvest and postharvest operations was lower with long awns, farmers have maintained a selective pressure in order to keep the long awns. For instance, Hua et al. (2015) reported from the ancient Chinese texts that farmers continued to use rice landraces with long awns and have given names to accessions based on these characteristics such as the ability to "choke a boar". This second case explains, at least partly, that long awns have persisted in some landraces, even until nowadays.

A second line of argument also explains the persistence of long awns. Recent genetic researches about rice have identified the major genes controlling seed shattering, sh4 and $q S H 1$ (Konishi et al. 2006; Li et al. 2006). However, neither the mutations in the major-effect shattering loci are alone sufficient to produce the non-shattering phenotype in wild rice (Ishikawa et al. 2010). This implies that single change in the wild ancestor may not have had immediate phenotypic effects until the overall genetic framework was sufficiently modified by other mutations (Ray and Chakraborty 2018). Under this scenario, other mechanisms to enhance seed retention would also have been selected upon, such as a mechanism based on 
changes of the architecture of the inflorescence (Ishii et al. 2013; Ishii and Ishikawa 2018); such as in Oryza rufipogon, the wild progenitor of domesticated rice $(O$. sativa $)$, the panicle could be either open or spreading. However, Ishii et al. (2013) discovered that one of the many early genetic mutations in rice, namely a mutation in a single locus, the SPR3 locus on chromosome 4, converts the open-panicle architecture of the wild species to the closed panicle of domesticated rice, leading to approximately 50\% gain in number of seeds recovered at maturity over a typical wild spreading inflorescence type. In order to achieve this, the presence of awns is required. Indeed, one of the consequences of the change from a spreading to a closed panicle in the wild species is to allow the awns of lower florets, which are now closely aligned with the main axis of the inflorescence, to retard the dropping of seeds in the upper portions of the inflorescence by acting as a net to catch them. In other words, early cultivators may have selected long awns because when they were associated with a closed panicle, seed retention was improved and so the harvest efficiency was higher. The third line of argument proceeds differently, i.e., the persistence of long awns can be the unintended consequence of the strong selection pressure early cultivators have implemented in order to fix the non-shattering trait. Magwa et al. (2016) have revealed the existence of a genetic linkage of awn presence and grain shattering which could be due to natural selection. Indeed, sf0136352825, the lead SNP associated with awn length was found to be less than 95 $\mathrm{kb}$ away from $q S H 1$. The role of natural selection in this genetic linkage comes from the fact that in wild rice seed awn length and shattering are both important factors in aiding seed dispersal, burial, and in protecting grains from animal predation. With such linkage, the selection of either trait could automatically lead to the selection of the other trait. On the contrary, human selection of a favorable mutant may lead to the transfer of unfavorable allele of the other trait. This co-transfer is due to the close linkage of the two genes and would make it difficult to select for a plant with both absence of awns and non-shattering grains at least in 
some cases. Since artificial selection has focused, on the loss of seed dispersal (i.e., on the acquisition of non-shattering trait), this may explain the subsequent attempt to remove seed dispersal aids that have failed for some landraces.

The three previous lines of argument are leading to the same conclusion: long awns may have persisted - for different and possibly complementary reasons - long after the fixation of the non-shattering trait, and even beyond the introduction of the sickle. Thus, the reduction of awns cannot be considered as a domestication syndrome trait but rather suits as a crop improvement trait.

\section{Conclusion}

Awn, an important appendage of wild progenitors of Asian cultivated rice (Oryza sativa L.), underwent phenotypic modification while domesticated . Efforts to elucidate the features and roles of awns are crucial to improve our understanding of the past, i.e., the initial domestication process of the cereals. The model of awn evolution in rice explicitly recognizes awn reduction as a key domestication syndrome trait. We demonstrate that ancient farmers may have benefitted from awn retention, that reduced seed predation and also facilitated harvest, thus, leading to an increased yield and labor-efficiency. Our analyses also revealed an absence of archeological records to track the transition culminated in shorter or lost awns, underlying complex genetics, and high phenotypic diversity that are not concordant with awn abolishment prior to domestication. Perhaps, our reasoning emphasized that awns have persisted long after domestication, and even after attainment of non-shattering. Building on these, we propose that awns were not essential to rice domestication, i.e., were not a domestication syndrome trait but underwent significant change during crop improvement phase. 
Our findings has not only contradicted the existing framework of Asian rice domestication, but also kindled several other questions, such as, what could be the pristine domestication syndrome traits in rice? Given our previous arguments (Ray and Chakraborty 2018) and current narrative, the fixation of non-shattering trait and reduction of awn may not be reliable markers of domestication. The next key question, contingent on the first, is to unravel the pace of domestication, i.e., whether it was relatively faster or protracted? The answers are crucial to gain a clear insight into the rice domestication process, currently which is relatively little examined compared to the Near Eastern crops.

\section{Acknowledgements}

The authors thank two anonymous referees. They also acknowledge the constructive criticisms by Utpal Basu, department of Molecular Biology and Biotechnology, University of Kalyani. Authors would like to thank Abhra Chakraborty for providing the photographs of awns. The usual caveat applies.

\section{References}

Abbo, S., Lev-Yadun, and A. Gopher. 2014a. The 'human mind' as a common denominator in plant domestication. Journal of Experimental Botany 65: 1917-1920.

Abbo, S., Pinhasi van-Oss, R., Gopher, A., Saranga, Y., Ofner, I., and Z. Peleg. 2014b. Plant domestication versus crop evolution: A conceptual framework for cereals and grain legumes. Trends in Plant Science 19: 351-360.

Abbo, S. and A. Gopher. 2017. Near Eastern Plant Domestication: A History of Thought. Trends in Plant Science 226: 491-511.

Allaby, R.G. 2010. Integrating the processes in the evolutionary system of domestication, Journal of Experimental Botany 614: 935-944. 
Asouti, E. and D. Fuller. 2013. A Contextual Approach to the Emergence of Agriculture in Southwest Asia: Reconstructing Early Neolithic Plant-Food Production. Current Anthropology 543: 299 -345.

Bessho-Uehara, K., Wang, D.R., Furuta, T., Minami, A., Nagai, K., Gamuyao, R., Asano, K., Angeles-Shim, R.B., Shimizu, Y., Ayano, M. and N. Komeda. 2016. Loss of function at RAE2, a previously unidentified EPFL, is required for awnlessness in cultivated Asian rice. Proceedings of the National Academy of Sciences USA 113: 8969-8974.

Brown, T.A., Jones, M.K., Powell, W. and R.G. Allaby. 2009. The complex origins of domesticated crops in the Fertile Crescent. Trends in Ecology \& Evolution, 24(2): 103-109. Deb, D., Bhattacharya, D., Jana, K.K., Mahato, R., Pramanik, R., Ram, A., Sinha, S. 2005. Seeds of Tradition, Seeds of Future: Folk Rice Varieties of Eastern India. Edition: 1st Publisher: Research Foundation for Science Technology and Ecology, New Delhi.

Doebley, J.F., B.S. Gaut and B.D. Smith. 2006. The molecular genetics of crop domestication, Cell 1277: 1309-21.

Elbaum, R., Zaltzman, L., Burgert, I., Fratzl, P. 2007. The role of wheat awns in the seed dispersal unit. Science 316: 884-886.

Fuller, D.Q. 2007. Contrasting patterns in crop domestication and domestication rates: recent archaeological insights from the Old World. Annals of Botany 100: 903-924. Fuller, D.Q. 2010. An Emerging Paradigm Shift in the Origins of Agriculture. General Anthropology, Bulletin of the General Anthropology Division 17(2): 1-12. Fuller, D.Q., Harvey, E. and Qin, L. 2007. Presumed domestication? Evidence for wild rice cultivation and domestication in the fifth millennium BC of the Lower Yangtze region. antiquity, 81(312): 316-331. Fuller, D.Q., Qin, L., and E. Harvey. 2008. Evidence for a late onset of agriculture in the Lower Yangtze region and challenges for an archaeobotany of rice. In: Sanchez-Mazas, A, 
Blench, R, Ross, MD, Peiros, I, Lin, M. (eds), Past Human Migrations in East Asia: Matching Archaeology, Linguistics and Genetics. London and New York: Routledge, 40-83.

Fuller, D.Q. and R. Allaby. 2009. Seed dispersal and crop domestication: shattering, germination and seasonality in evolution under cultivation. Annual Plant Reviews: Fruit Development and Seed Dispersal 38: 238-295.

Fuller, D.Q., Qin, L., Zheng, Y., Zhao, Z., Chen, X., Hosoya, L.A. and G.P. Sun. 2009. The domestication process and domestication rate in rice: spikelet bases from the Lower Yangtze. Science 323(5921): 1607-1610.

Fuller, D.Q., Allaby, R.G., and C. Stevens. 2010. Domestication as innovation: the entanglement of techniques, technology and chance in the domestication of cereal crops. World Archaeology 42: 13-28.

Fuller, D.Q., Denham, T., Arroyo-Kalin, M., Lucas, L., Stevens, C.J., Qin, L., Allaby, R.G. and M.D. Purugganan. 2014. Convergent evolution and parallelism in plant domestication revealed by an expanding archaeological record. Proceedings of the National Academy of Sciences USA 111: 6147-6152.

Fuller, D.Q., Stevens, C., Lucas, L., Murphy, C., and L. Qin. 2016. Entanglements and entrapment on the pathway toward domestication. In: Der, L., Fernandi, F. (eds), Archaeology of entanglement. Left Coast Press, Los Angeles: 151-172.

Gepts, P. 2004. Crop domestication as a long term selection experiment. Plant Breeding Review 24: 1-44.

Gu, B., Zhou T, Luo, J., Gu, B., Zhou, T., Luo, J., Liu, H., Wang, Y., Shangguan, Y., Zhu, J., Li, Y., Sang, T., Wang, Z. and Han, B. 2015. An-2 encodes a cytokinin synthesis enzyme that regulates awn length and grain production in rice. Molecular Plant 8: 1635-1650.

Guo, Z. and T. Schnurbusch. 2016. Costs and benefits of awns. Journal of Experimental Botany 67(9): 2533-2535. 
Hammer, K. 1984. Das Domestikations syndrom. Die Kulturpflanze 32: 11- 34.

Harlan, J.R., Wet. J., and Price E.G. 1973. Comparative Evolution of Cereals. Evolution, 27: 311-325. doi: 10.2307/2406971.

Harris, D.R. 1989. An evolutionary continuum of people-plant interaction. In: Harris D.R., and Hillman, G.C. (eds). Foraging and farming: the evolution of plant exploitation. London: Routledge, 11-26.

Helbaek, H. 1959. Domestication of Food Plants in the Old World: Joint efforts by botanists and archeologists illuminate the obscure history of plant domestication. Science 130(3372): $365-72$.

Hu, G., Zhang, D., Pan, H., Li, B., Wu, J., Zhou, X., Zhang, Q., Zhou, L., Yao, G., Li, J. and Li, J., 2011. Fine mapping of the awn gene on chromosome 4 in rice by association and linkage analyses. Chinese Science Bulletin 56(9): 835-839.

Hua, L., Wang DR, Tan L, Fu, Y., Liu, F., Xiao, L., Zhu, Z., Fu, Q., Sun, X., Gu, P. and Cai, H., 2015. LABA1, a domestication gene associated with long, barbed awns in wild rice. The Plant Cell 27: 1875-1888.

Ikemoto, M. Ikemoto, M., Otsuka, M., Thanh, P.T., Phan, P.D.T., Ishikawa, R. and Ishii, T., 2017. Gene interaction at seed-awning loci in the genetic background of wild rice. Genes \& genetic systems 92(1): 21-26.

Ishii, T., Numaguchi, K., Miura, K., Yoshida, K., Thanh, P.T., Htun, T.M., Yamasaki, M., Komeda, N., Matsumoto, T., Terauchi, R. and Ishikawa, R. 2013. OsLG1 regulates a closed panicle trait in domesticated rice. Nature Genetics 45(4): 462-465.

Ishii, T., and R. Ishikawa. 2018. Domestication Loci Controlling Panicle Shape, Seed Shattering, and Seed Awning. In: Sasaki, T., Ashikari, M. (eds), Rice Genomics, Genetics and Breeding, pp 207-221. Springer, Singapore. https://doi.org/10.1007/978-981-10-7461-5_12 
Ishikawa, R., Thanh, P. T., Nimura, N., Htun, T. M., Yamasaki,. M., and T. Ishii, T. 2010. Allelic interaction at seed-shattering loci in the genetic backgrounds of wild and cultivated rice species. Genes Genet. Syst 85: 265-271.

Jin, J., Hua, L., Zhu, Z., Tan, L., Zhao, X., Zhang, W., Liu, F., Fu, Y., Cai, H., Sun, X. and P. Gu. 2016. GAD1 encodes a secreted peptide that regulates grain number, grain length and awn development in rice domestication. Plant Cell 28: 2453-2463.

Konishi, S., Izawa, T., Lin, S.Y., Ebana, K., Fukuta, Y., Sasaki, T. and M. Yano. 2006. An SNP caused loss of seed shattering during rice domestication. Science 312(5778): 1392-1396. Larson, G., Piperno, D.R., Allaby, R.G., Purugganan, M.D., Andersson, L., Arroyo-Kalin, M., Barton, L., Vigueira, C.C., Denham, T., Dobney, K. and A.N. Doust. 2014. Current perspectives and the future of domestication studies. Proceedings of the National Academy of Sciences USA 111(17): 6139-6146.

Li. C., Zhou. A., and T. Sang. 2006. Rice domestication by reducing shattering. Science 311: 1936-1939.

Luo, J., Liu, H, Zhou, T., Gu, B., Huang, X., Shangguan, Y., Zhu, J., Li, Y., Zhao, Y., Wang, Y. and Q. Zhao. 2013. An-1 encodes a basic helix-loop-helix protein that regulates awn development, grain size, and grain number in rice. The Plant Cel 25: 3360-3376.

Maeda, O., Lucas, L., Silva, F., Tanno, K.I. and D.Q. Fuller. 2016. Narrowing the harvest: Increasing sickle investment and the rise of domesticated cereal agriculture in the Fertile Crescent. Quaternary Science Reviews 145: 226-237.

Magwa, R.A., Zhao, H., Yao, W., Xie, W., Yang, L., Xing, Y. and X. Bai. 2016.

Genomewide association analysis for awn length linked to the seed shattering gene qSH1 in rice. Journal of Genetics 95(3): 639-646.

Meyer, R.S. and M.D. Purugganan. 2013. Evolution of crop species: genetics of domestication and diversification. Genetics 14: 840-852. 
Olsen, K.M. and J.F. Wendel. 2013. A Bountiful Harvest: Genomic Insights into Crop Domestication Phenotypes. Annual Reviewof Plant Biology 64: 47-70.

Pingali, P.L. 2012. Green Revolution: Impacts, limits, and the path ahead. Proceedings of the National Academy of Sciences USA 109(31): 12302-12308.

Purugganan, M. D., and D. Q. Fuller. 2011. Archaeological data reveal slow rates of evolution during plant domestication. Evolution 65: 171-183.

Ray, A. and D. Chakraborty. 2018. Shattering or not shattering: that is the question in domestication of rice (Oryza sativa L.). Genetic Resourceand Crop Evolution 65(2): 391-395. Singh. S., Singh, T.N., and J.S. Chauhan. 2009. Architectural engineering of rice panicle for increased productivity: A powerful biological tool for combating agricultural water crisis. Journal of Crop improvement 23(4): 451-66.

Svizzero, S. 2018. Plant domestication more rapid under optimizing behavior, Journal of Bioeconomics 20(3): 287-308. DOI: 10.1007/s10818-018-9272-4.

Tanno, K. I., and G. Willcox, G. 2006. How fast was wild wheat domesticated? Science 311; 1886.

Toriba, T., Suzaki, T., Yamaguchi, T., Ohmori, Y., Tsukaya, H. and H-Y Hirano. 2010. Distinct regulation of adaxial-abaxial polarity in anther patterning in rice. Plant Cell 22: $1452-1462$.

Toriba T. and H.-Y. Hirano.2014. The DROOPING LEAF and OsETTIN2 genes promote awn development in rice. Plant Journal 77: 616-626.

Tzarfati, R., Saranga, Y., Barak, V., Gopher, A., Korol, A. B., and S. Abbo. 2013. Threshing efficiency as an incentive for rapid domestication of emmer wheat. Annals of Botany 112: 829-837. 
Winterhalder, B. and D. J. Kennett. 2006, Behavioral ecology and the transition from hunting and gathering to agriculture. In Behavioral Ecology and the Transition to Agriculture, eds. D.J. Kennett and B. Winterhalder. 1-21, Berkeley: University of California Press.

Zhang, L.B., Zhu, Q., Wu, Z.Q., Ross-Ibarra, J., Gaut, B.S., Ge, S. and T. Sang. 2009.

Selection on grain shattering genes and rates of rice domestication. New Phytologist 184(3): 708-720.

Zohary, D. 2004. Unconscious Selection and the Evolution of Domesticated Plants, Economic Botany 58(1): 5-10. 


\section{Figures and Tables Captions}

Table 1: A non-exhaustive list of Indian rice landraces having different awn length (in millimeter) taken from Deb et al. (2005).

Table 2: Influence of awns on yield, harvest, and post-harvest efficiency, when the basket beating method is used for harvesting, and that most - if not all - panicles are shattering

Figure 1: A spectrum of diversity of awn length in modern landraces (a. Rahapanjar, b. Sada Kaya, c. Shimul kuri, d. Gangajali, e. Kalonunia, f. Tulaipanji) (in mm)

Figure 2: Comparative evolution of food production technologies, harvesting methods and the presence of awns (from the Mesolithic to nowadays). 
Table 1: A non-exhaustive list of Indian rice landraces having different awn length (in millimeter) taken from Deb et al. (2005).

\begin{tabular}{|l|l|l|l|}
\hline \multicolumn{1}{|c|}{ Awnless rice } & \multicolumn{1}{|c|}{ Very short awn rice } & \multicolumn{1}{|c|}{ Short awn rice } & \multicolumn{1}{|c|}{ Long/very long awn rice } \\
\hline Agni-sal & Budbud-Sal (1.7) & Lal Panati $(9.0)$ & Kalma (21) \\
\hline Bansh Kathi & Chaitanya (3.25) & Nata $(11.1)$ & Shimul Kuri (28.1) \\
\hline Chini Atap & Jal Kamini (2.07) & Niroja (7.47) & Sada Jira/Sada Bhog (23.2) \\
\hline Dumur-Sal & Kalo Boro (3.0) & Noichi (8.5) & Shatia (33.0) \\
\hline Gandheswari & Kanakchur (3.33) & Parmai-Sal (5.87) & Bhim-sal (33.7) \\
\hline Jamai-Sal & Kuro Bagar (4.7) & Ratul Aush (8.6) & Gangajali (37.9) \\
\hline Kaminibhog & Marich-Sal (3.2) & Sada Kaya (9.27) & Kaya Kelas (40.5) \\
\hline Olee & Radhuni Pagal (2.8) & Shotput (9.2) & Kakua (53.1) \\
\hline
\end{tabular}

Table 2: Influence of awns on the yield, harvest, and post-harvest efficiency, when the basket beating method is used for harvesting, and that most - if not all panicles are shattering

\begin{tabular}{|l|c|c|}
\hline & $\begin{array}{c}\text { Awned } \\
\text { Long awns }\end{array}$ & $\begin{array}{c}\text { Awnless } \\
\text { No or short awns }\end{array}$ \\
\hline $\begin{array}{l}\text { Yield } \\
\text { or pre-harvest production }\end{array}$ & high & low \\
\hline $\begin{array}{l}\text { Harvest efficiency } \\
\text { with the basket beating }\end{array}$ & high & low \\
\hline $\begin{array}{l}\text { Efficiency of post-harvest operations } \\
\text { threshing, processing, storage }\end{array}$ & low & \\
\hline
\end{tabular}


